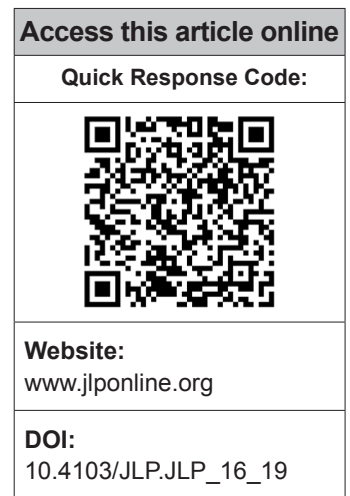

Departments of Pathology and ${ }^{1}$ Otorhinolaryngology, North Eastern Indira

Gandhi Regional Institute of Health and Medical

Sciences, Shillong, Meghalaya, India

Address for correspondence: Dr. Biswajit Dey, Department of Pathology, North Eastern Indira Gandhi Regional Institute of Health and Medical Sciences, Mawdiangdiang, Shillong - 793018 , Meghalaya, India.

E-mail: drbish25@ rediffmail.com

Submission: 28-01-2019 Accepted: 25-04-2019

\title{
Castleman's disease associated with calcifying fibrous tumor: A rare association with review of literature
}

\author{
Evarisalin Marbaniang, Yookarin Khonglah, Biswajit Dey, Brian Shunyu', \\ Bidyut Gogoi
}

Abstract:

Castleman's disease is a rare disease characterized by unicentric or multicentric enlargement of the lymph node, and it is mostly of the hyaline vascular type. Calcifying fibrous tumor is a neoplasm characterized by large areas of hyalinized collagen with paucicellular areas along with dystrophic calcification and scattered lymphoplasmacytic infiltrates. There are only five case reports to describe an association between these two entities. We report a case of a 38-year-old male with seropositivity for hepatitis $B$ virus presenting with a right-sided cervical swelling. Fine-needle aspiration cytology (FNAC) was done, and a diagnosis of follicular hyperplasia was offered. Biopsy confirmed the diagnosis of Castleman's disease. However, there was associated calcifying fibrous tumor in the lymph node induced by trauma due to FNAC.

Key words:

Castleman's disease, hepatitis B virus, lymph node

\section{Introduction}

C astleman's disease is an uncommon disorder presenting as unicentric or multicentric Castleman's disease (MCD) enlargement of the lymph node. It is usually of the hyaline vascular type, or the plasma cell type, or mixed variant. ${ }^{[1]}$ Castleman's disease of hyaline vascular type is known to have nonneoplastic proliferations of spindle cells in compact tangles as well as neoplastic oval-to-spindle cells intermixed with lymphocytes. ${ }^{[1,2]}$ Reports have shown association of hyaline vascular type Castleman's disease with calcifying fibrous tumor, which is a benign tumor of unknown pathogenesis. ${ }^{[2-6]}$ We report a case of hyaline vascular type Castleman's disease in a 38-year-old male, diagnosed on fine-needle aspiration cytology (FNAC) and subsequently developing calcifying

This is an open access journal, and articles are distributed under the terms of the Creative Commons Attribution-NonCommercial-ShareAlike 4.0 License, which allows others to remix, tweak, and build upon the work non-commercially, as long as appropriate credit is given and the new creations are licensed under the identical terms.

For reprints contact: reprints@medknow.com fibrous pseudotumor in the Castleman's disease.

\section{Case Report}

A 38-year-old male presented with the complaint of right-sided cervical swelling over a duration of 4 months. There was associated discomfort and pain. There was no change of voice or difficulty in swallowing. There was no fever or a history of contact with tuberculosis. The patient was seroreactive for hepatitis B surface antigen. On examination, there was an enlarged right-sided Level III cervical lymph node measuring $4 \mathrm{~cm} \times 3 \mathrm{~cm} \times 1 \mathrm{~cm}$. It was mildly tender. No sinus discharge was noted.

FNAC was done from the cervical lymph node. The smears were cellular and showed mixed population of small and large lymphoid cells with predominance of small, mature lymphocytes [Figure 1a]. Follicular

\footnotetext{
How to cite this article: Marbaniang $E$, Khonglah $Y$, Dey B, Shunyu B, Gogoi B. Castleman's disease associated with calcifying fibrous tumor: A rare association with review of literature. J Lab Physicians 2019;11:171-3.
} 
dendritic cells (FDCs) were present in clusters and single. They had abundant pale cytoplasm, with frequent streaking and indistinct cytoplasmic borders. Few plasma cells and tangible macrophages were noted in the background. There were no eosinophils, epithelioid giant cells, or necrosis. Based on cytological features, a diagnosis of follicular hyperplasia was offered.

A total excision biopsy of the lymph node was done. Grossly, the lymph node measured $4 \mathrm{~cm} \times 3.2 \mathrm{~cm} \times 1.2 \mathrm{~cm}$ and was gray white. Histopathological features were those of hyaline vascular type Castleman's disease, with broad mantle zone showing concentric layering of peripheral lymphocytes resembling onion skin and interfollicular areas showing increased thick hyalinized vessels and some penetrating into the germinal centers [Figure 1b]. Some follicles showed a radially penetrating sclerotic vessel in the germinal center as evidenced by CD34 positivity [Figure 1c]. Again, around the periphery of the lymph node tissue and also dissecting it at some areas was an abundant mass of hyalinized collagenous fibrosclerotic tissue with paucicellular spindle cell proliferation [Figure 1d]. These hyalinized areas were punctuated by numerous dystrophic calcified areas, with some showing psammomatous changes.

Altogether, these features confirmed the diagnosis of a Castleman's disease of hyaline vascular type associated with calcifying fibrous tumor.

\section{Discussion}

Association of Castleman's disease with calcifying

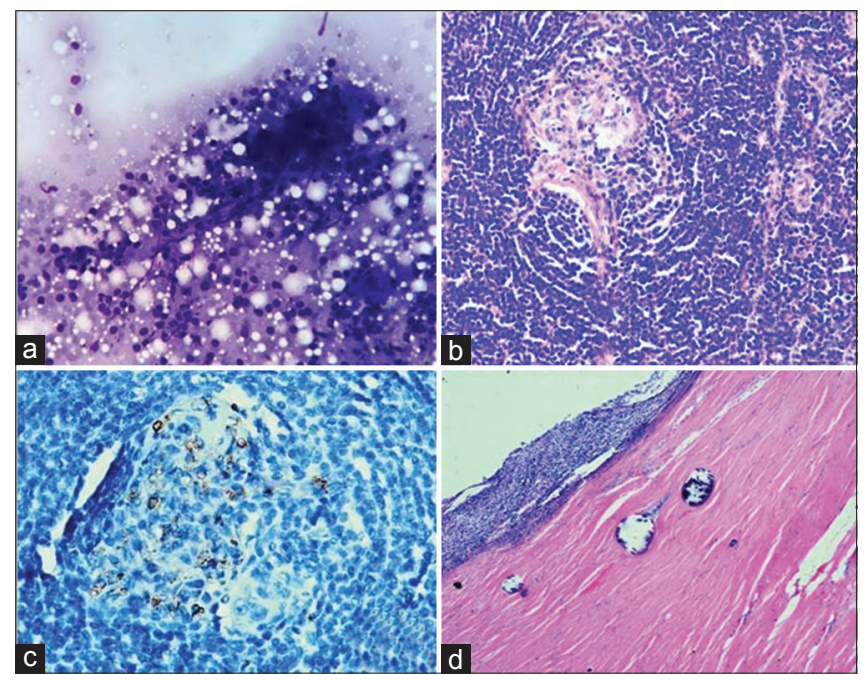

Figure 1: (a) Cellular smear showing mixed population of small and large lymphoid cells with predominance of small, mature lymphocytes (Pap, $\times 10)$. (b) Histopathology showing follicles with concentric onion ring formation of mantle zone with hyalinized vessel in the germinal center $(\mathrm{H}$ and $\mathrm{E}, \times 10)$. (c) CD34-positive staining highlighting the sclerotic radiating vessel in the germinal center (IHC, $\times 40)$.

(d) Histopathology showing paucicellular hyalinized collagenous tissue with dystrophic calcification surrounding the lymphoid tissue ( $\mathrm{H}$ and $\mathrm{E}, \times 10)$ fibrous tumor is extremely rare with only five case reports been reported in literature ${ }^{[2-6]}$ [Table 1].

Castleman's disease, also known as angiofollicular lymph node hyperplasia, is an uncommon lymphoproliferative disorder first described in 1954. ${ }^{[1]}$ Although the histopathological features of Castleman's disease are well established, the diagnosis is challenging on cytology as often the diagnosis is missed or is misdiagnosed as lymphoma. ${ }^{[1]}$ Cytomorphologically, Castleman's disease shows polymorphous population of lymphoid cells with a predominance of small lymphocytes..$^{[1]}$ FDCs are seen admixed with lymphocytes. ${ }^{[1]}$ These FDCs have fine chromatin with small nucleoli and abundant pale cytoplasm with indistinct cytoplasmic margins. ${ }^{[1]}$ The cytomorphological features which are highly suggestive of hyaline vascular type Castleman's disease are the presence of "dysplastic" FDCs and hyalinized capillaries. ${ }^{[1]}$ Lymphocyte emperipolesis is another cytological feature described. ${ }^{[1]}$ In plasma cell type of Castleman's disease, plasma cells and plasmablasts are seen in a background of polymorphous lymphoid population. ${ }^{[1]}$ All the features may not be present on cytology, so subtyping of Castleman's disease solely on cytological features is not recommended. ${ }^{[1]}$

Over the last decades, human herpesvirus-8 (HHV-8) infection which was detected in all human immunodeficiency virus (HIV)-related MCD was found to play a significant role in the pathogenesis of HIV-related MCD.${ }^{[7]}$ However, HHV-8 was negative in approximately $60 \%$ of HIV-unrelated MCD. ${ }^{[7]}$ A study done by Yuan et al. reported a high incidence of hepatitis $B$ virus infection in HIV-negative Castleman's disease. ${ }^{[8]}$ Here, we report the coexistence of hepatitis B in the patient. The role of hepatitis B in the pathogenesis of Castleman's disease is still not known even though for HIV and HHV-8 it has always been mentioned in the literature. ${ }^{[7,8]}$

Calcifying fibrous tumor, also known as calcifying fibrous pseudotumor, was first described by Rosenthal and Karim in 1988 as "childhood fibrous tumors with psammoma bodies." ${ }^{\prime[9]}$ It is a rare benign fibrous lesion affecting children and young adults. Calcifying

Table 1: Cases of Castleman's disease associated with calcifying fibrous tumor reported in literature

\begin{tabular}{lclll}
\hline Authors & $\begin{array}{c}\text { Age } \\
\text { (years) }\end{array}$ & Sex & Site \\
\hline Dargent et al. 1999 & 9 & Male & Right inguinal lymph node \\
Azam et al. 2009 & 13 & Male & Greater curvature of stomach \\
Valladolid et al. 2014 & 25 & Female & Distal ileum \\
Ma et al. 2015 & 34 & Male & Mesentery \\
Harmankaya et al. & 15 & Female & Right supraclavicular lymph \\
2018 & & & node \\
Present case & 38 & Male & Right cervical lymph node \\
\hline
\end{tabular}


fibrous tumor is characterized by bland spindle cells embedded in abundant collagenous matrix, interspersed dystrophic or psammomatous calcifications, and lymphoplasmacytic infiltrate..$^{[2,3]}$ Although examples have followed trauma and have occurred in association with Castleman's disease, the pathogenesis remains unknown. ${ }^{[4,10]}$ However, the underlying process is likely to be fibroinflammatory and reactive in nature. ${ }^{[10]}$ There are examples which have followed trauma and history of trauma to the affected site in the form of a fine-needle aspiration being performed before the biopsy. ${ }^{[3,10]}$ In the present case report, there was trauma in the form of a FNAC being performed before the excision biopsy was done, which might have been involved in the healing process and contributed to the formation of these features of a calcifying fibrous tumor.

The present case is discussed due to the rare association between two uncommon entities. Trauma like FNAC often leads to calcifying fibrous tumor-like features in Castleman's disease. Furthermore, the present case emphasizes the role of hepatitis B virus infection, which requires further elucidation, in the pathogenesis of Castleman's disease.

\section{Declaration of patient consent}

The authors certify that they have obtained all appropriate patient consent forms. In the form the patient(s) has / have given his/her/their consent for his/her/their images and other clinical information to be reported in the journal. The patients understand that their names and initials will not be published and due efforts will be made to conceal their identity, but anonymity cannot be guaranteed.

\section{Financial support and sponsorship} Nil.

\section{Conflicts of interest}

There are no conflicts of interest.

\section{References}

1. Murro D, Agab M, Brickman A, Loew J, Gattuso P. Cytological features of Castleman disease: A review. J Am Soc Cytopathol 2016;5:100-6.

2. Dargent JL, Delplace J, Roufosse C, Laget JP, Lespagnard L. Development of a calcifying fibrous pseudotumour within a lesion of Castleman disease, hyaline-vascular subtype. J Clin Pathol 1999;52:547-54.

3. Azam M, Husen YA, Pervez S. Calcifying fibrous pseudotumor in association with hyaline vascular type Castleman's disease. Indian J Pathol Microbiol 2009;52:527-9.

4. Valladolid G, Weisenberg E, Sundaresan R, Maker AV. Calcifying fibrous tumor of the small intestine associated with Castleman-like lymphadenopathy. J Gastrointest Surg 2014;18:1205-8.

5. $\mathrm{Ma} \mathrm{H}$, Jiang $\mathrm{M}$, Xiao $\mathrm{W}$. A rare stroma-rich variant of hyaline-vascular Castleman's disease associated with calcifying fibrous pseudotumor. Int J Clin Exp Pathol 2015;8:3362-4.

6. Harmankaya İ, Ugras NS, Sekmenli T, Demir F, Köksal Y. Calcified fibrous pseudotumor with Castleman disease. Autops Case Rep 2018;8:e2018033.

7. Soulier J, Grollet L, Oksenhendler E, Cacoub P, Cazals-Hatem D, Babinet $\mathrm{P}$, et al. Kaposi's sarcoma-associated herpesvirus-like DNA sequences in multicentric Castleman's disease. Blood 1995;86:1276-80.

8. Yuan XG, Chen FF, Zhu YM, Hu W, Zhao XY, Jin J. High prevalence of hepatitis $B$ virus infection in HIV-negative Castleman's disease. Ann Hematol 2012;91:857-61.

9. Rosenthal NS, Abdul-Karim FW. Childhood fibrous tumor with psammoma bodies. Clinicopathologic features in two cases. Arch Pathol Lab Med 1988;112:798-800.

10. Zámecník M, Dorociak F, Veselý L. Calcifying fibrous pseudotumor after trauma. Pathol Int 1997;47:812. 